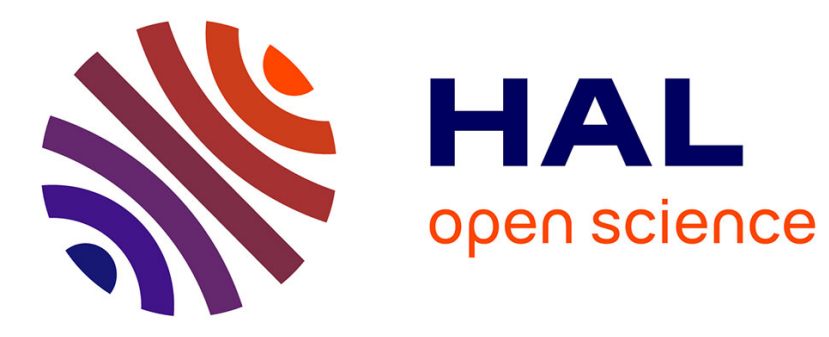

\title{
Luminescence of sensitive materials: towards new optical sensing
}

Lucile Cornu, Manuel Gaudon, S. Ilin Evgeniy, Cyril Aymonier, Philippe

Veber, Alain Garcia, Myrtil L. Kahn, Yohan Champouret, Veronique Jubera

\section{- To cite this version:}

Lucile Cornu, Manuel Gaudon, S. Ilin Evgeniy, Cyril Aymonier, Philippe Veber, et al.. Luminescence of sensitive materials: towards new optical sensing. SPIE Photonics West 2015: OPTO, Optical Society of America, Feb 2015, San Francisco, United States. 936416 (7 p.), 10.1117/12.2076948. hal-03136317

\section{HAL Id: hal-03136317 https://hal.science/hal-03136317}

Submitted on 9 Feb 2021

HAL is a multi-disciplinary open access archive for the deposit and dissemination of scientific research documents, whether they are published or not. The documents may come from teaching and research institutions in France or abroad, or from public or private research centers.
L'archive ouverte pluridisciplinaire $\mathbf{H A L}$, est destinée au dépôt et à la diffusion de documents scientifiques de niveau recherche, publiés ou non, émanant des établissements d'enseignement et de recherche français ou étrangers, des laboratoires publics ou privés. 


\title{
Luminescence of sensitive materials: towards new optical sensing
}

\author{
Lucile Cornu, ${ }^{\mathrm{a}, \mathrm{b}}$ Manuel Gaudon, ${ }^{\mathrm{a}, \mathrm{b}}$ Evgeniy Ilin, ${ }^{\mathrm{a}, \mathrm{b}}$ Cyril Aymonier, ${ }^{\mathrm{a}, \mathrm{b}}$ Philippe Veber, ${ }^{\mathrm{a}, \mathrm{b}}$ Alain \\ Garcia, ${ }^{a, b}$ Myrtil Kahn, ${ }^{c}$ Yohan Champouret, ${ }^{c}$ Veronique Jubera ${ }^{* a, b}$ \\ ${ }^{a}$ CNRS, ICMCB, UPR 9048, F-33600 Pessac, France \\ ${ }^{\mathrm{b}}$ Univ. Bordeaux, ICMCB, UPR 9048, F-33600 Pessac, France \\ ${ }^{c}$ Laboratoire de Chimie de Coordination, UPR8241 CNRS, F-31077 Toulouse, France \\ *jubera@icmcb-bordeaux.cnrs.fr
}

\begin{abstract}
In the last decades, considerable efforts have been carried out to develop new tools and knowledge in the domain of functionalized materials, for application ranging information, lighting, communication, energy, optical sources or detection. To couple an optical answer with another property is possible through the follow-up of the luminescence. The control of the structural symmetry, oxidation state or surface chemistry enables the chemists to precisely tune the emission. Illustrations will be provided on inorganic powder and crystal materials.
\end{abstract}

Keywords: Sensitive materials, luminescence, X-chrome, photoactive materials, sensors, data storage

\section{1- INTRODUCTION}

Functionalized materials have been drawing significant interest in the domain of application ranging information, lighting, communication, energy, optical sources or detection [1]. The control of the structural symmetry, oxidation state or surface chemistry enables the chemists to precisely tune the emission. For instance:

(i) A red to green luminescence switch occurres for manganese doped spinel treated between $1200^{\circ} \mathrm{C}$ and $1350^{\circ} \mathrm{C}$. By modifying the stoichiometry, it is possible to change the temperature range of this luminescence spectrum switch [2,3].

(ii) UV irradiation of cerium doped indium elpasolite matrix leads to the decrease of the doping element emission in favor of a bright orange emission which results from the reduction of indium. The redox process is reversible under adequate irradiation or heat treatment temperature. The sensitized materials are stable over two decades, showing hence perfectly bi-stable state [4,5].

(iii) Emission of $\mathrm{ZnO}$ is strongly related to the synthesis route. Low operating temperature can result in the appearing of surface and bulk defects. Their existence impacts not only the emission wavelength but also its stability under specific atmosphere [6-9].

Tunable emission properties of these materials make them potential candidates for highly sensitive thermal, gas or photosensors.

\section{2- EXPERIMENTAL RESULTS AND DISCUSSION}

\subsection{Color switch due to luminescent cation migration $[2,3]$}

$\mathrm{ZnAl}_{2} \mathrm{O}_{4}$ spinel compound is an interesting material with a specific cubic crystallographic structure which possesses 64 tetrahedral sites and 32 octahedral sites. A doping with luminescent metallic cations such as transition metals or rare earth elements can be used to gain satisfying optical properties for flat panel displays [10] or as pigments in glazes or stonewares [11]. Indeed, one can modulate the location of the doping element by changing the experimental condition. The proportion of divalent cations in octahedral site is called inversion rate $(\boldsymbol{\delta})$ and can vary between 0 and 1 . A direct spinel structure is constituted by only 8 of the tetrahedral sites occupied by the $\mathrm{Zn}$ and 16 of the octahedral sites occupied by Al cations and the oxygen anions fully occupy the $32 e$ positions [12]. In $\mathrm{ZnAl}_{2} \mathrm{O}_{4}$, a part of $\mathrm{Zn}^{2+}$ cations is located in the $16 d$ sites and a part of $\mathrm{Al}^{3+}$ cations is located on the $8 a$ sites. In literature the $\delta$ parameter ranges between $0<\delta<0.05$ [13-15] for the $\mathrm{ZnAl}_{2} \mathrm{O}_{4}$ matrix. Because it has been demonstrated that the inversion rate is strongly linked to the experimental conditions [1620], we propose here to use a Pechini synthesis to have access to a large crystallite size distribution to impact the $\delta$ ratio [3]. To control the inversion factor of doped $\mathrm{ZnAl}_{2} \mathrm{O}_{4}$ materials may be of great interest especially when the luminescent properties are affected by the location of the emitting center, the crystal field strength. By 
consequence, divalent manganese was selected because of its appropriate optical transition (3d-3d) and its appropriate oxidation state and radius size.

The solubility limit of divalent manganese was controlled by XRD pattern and TEM-EDX analyses. Even if the $30 \%$ doped material clearly shows a secondary aluminum-rich phase $\left(\alpha-\mathrm{Al}_{2} \mathrm{O}_{3}\right.$ phase $\left.\mathrm{n}^{\circ} 00-046-1212\right), \mathrm{XRD}$ pattern and TEM -EDX show a pure spinel phase with experimental $\mathrm{Zn}: \mathrm{Mn}$ :Al concentrations close to the theoretical ones for the $15 \%$ doped-samples.

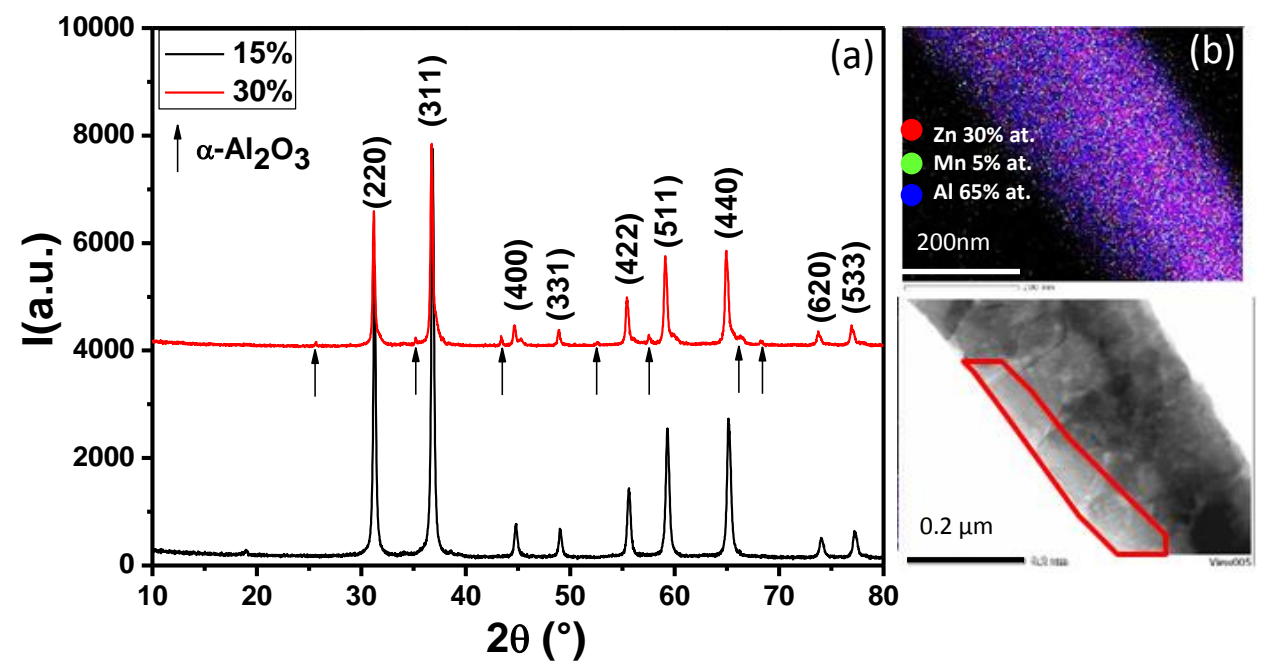

Figure 1- a) X-ray diffraction patterns of the $1000{ }^{\circ} \mathrm{C}$ heat-treated $\mathrm{Mn}$ doped samples (Red arrows show the secondary phase: $\alpha$ - $\mathrm{Al}_{2} \mathrm{O}_{3}$ corundum) and b) EDX-chemical maps of the $15 \%$ Mn-content compound (corresponding $\mathrm{Zn}$, Al and Mn molar percentages are reported in the figure)

Considering these results, manganese concentration was fixed at $0.5 \%$ to avoid precipitation of the alumina phase and potential concentration effect which may quench the manganese luminescence. Since it has not been possible to discriminate $\mathrm{Zn}$ from $\mathrm{Mn}$ ions because of the low doping rate and their vinicity in the periodic table, Rietveld refinements were performed to determine the global divalent cation inversion rate $\left(\boldsymbol{\delta}+\boldsymbol{\delta}^{\prime}\right)$ on the $0.5 \%$ $\mathrm{Mn}$-doped $\mathrm{ZnAl}_{2} \mathrm{O}_{4}$ compounds. Materials were heat-treated at various annealing temperatures ranging from $500^{\circ} \mathrm{C}$ to $1350^{\circ} \mathrm{C}$. Results obtained considering the $\left(\mathrm{Zn}_{0.995-\delta} \mathrm{Mn}_{0.005-\delta^{\prime}}, \mathrm{Al}_{\delta+\delta}\right)\left[\mathrm{Zn}_{\delta} \mathrm{Mn}_{\delta^{\prime}}, \mathrm{Al}_{2-\delta-\delta^{\prime}}\right] \mathrm{O}_{4}$ formulae are listed in Table 1.

Table 1. Structural parameters of the $0.5 \% \mathrm{Mn}$-doped $\mathrm{ZnAl}_{2} \mathrm{O}_{4}$ samples

\begin{tabular}{c|c|c|c|c}
$\mathrm{T}\left({ }^{\circ} \mathrm{X}\right)$ & $\delta+\delta^{\prime} *$ & $\mathrm{a}(\AA)$ & $\mathrm{Rp}$ & $\mathrm{R}$-Bragg \\
\hline 500 & 0.159 & $8.09(5)$ & 0.051 & 0.042 \\
600 & 0.087 & $8.08(9)$ & 0.067 & 0.026 \\
800 & 0.059 & $8.09(5)$ & 0.058 & 0.028 \\
1000 & 0.048 & $8.084(5)$ & 0.061 & 0.023 \\
1200 & 0.047 & $8.089(4)$ & 0.084 & 0.028 \\
1350 & 0.026 & $8.087(4)$ & 0.121 & 0.039
\end{tabular}

*global inversion rate, **with all-non excluded model and not corrected for background

None significant variation of the $\boldsymbol{a}$ cell parameter was observed as function of the temperature but a significant increase of the crystallite size is reported. The crystallites grow from about $20 \mathrm{~nm}$ for the lowest temperature up to $120 \mathrm{~nm}$ for the highest one with a decrease of the global inversion rate from $16 \%$ to $2.6 \%$. One can deduce that the annealing temperature impacts the cationic distribution within the spinel structure. This global inversion rate taking into account the manganese distribution, the influence of the doping element should be visible on the optical properties.

The emission properties of $\mathrm{Mn}$-doped $\mathrm{ZnAl}_{2} \mathrm{O}_{4}$ depend on the symmetry of the coordination polyhedron within the spinel network in which the manganese ion is introduced. A location in a tetrahedral environment is 
generally associated to a green luminescence of this element. A higher crystal field effect as in octahedral site shifts the emission to lower energy. Moreover, a blue shift of the metallic zinc-oxygen charge transfer band is detected between $1200^{\circ} \mathrm{C}$ and $1350^{\circ} \mathrm{C}$ on the diffuse reflectance spectra, this last thermal treatment leading to a total migration of the divalent cation into the fourfold coordination site [3]. The optical properties are illustrated for these two temperatures in Figure 2.

(a)

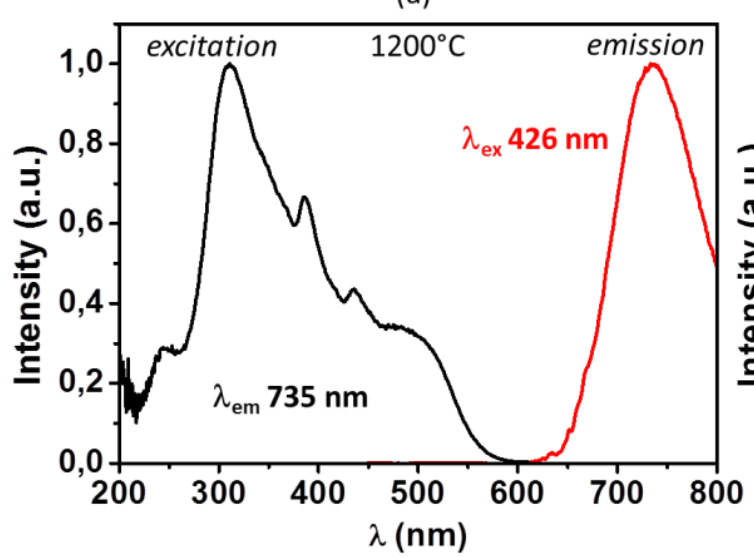

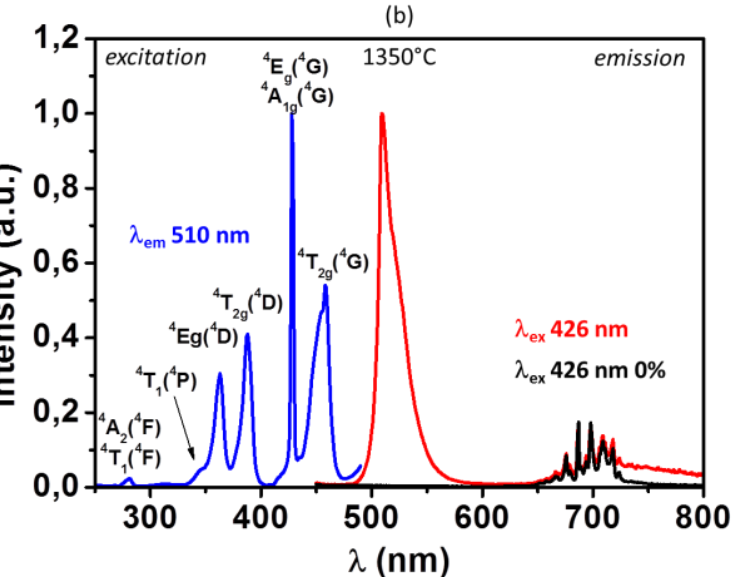

$\lambda(\mathrm{nm})$

Figure 2

Room temperature excitation and emission spectra of $0.5 \%$ Mn-doped $\mathrm{ZnAl}_{2} \mathrm{O}_{4}$ compound obtained after thermal treatment at (a) $1200{ }^{\circ} \mathrm{C}$ and (b) $1350{ }^{\circ} \mathrm{C}$.

The $1350^{\circ} \mathrm{C}$ treatment makes possible the obtaining of a total direct Mn-doped spinel i.e., with Mn ions fully located in the tetrahedral sites. Many papers have reported the green emission of this transition metal in a tetrahedral environment [21-23]. The main ${ }^{4} \mathrm{~T}_{1} \rightarrow{ }^{6} \mathrm{~A}_{1}$ transition is observed at $508 \mathrm{~nm}$. In addition vibronic vibrations are detected at $514 \mathrm{~nm}, 520 \mathrm{~nm}$ and $529 \mathrm{~nm}$, respectively. For an excitation at $426 \mathrm{~nm}$, red emission peaks ranging between $640 \mathrm{~nm}$ and $730 \mathrm{~nm}$ were attributed to trivalent chromium impurities coming from the raw reactant. The $1200^{\circ} \mathrm{C}$ sample possesses an inversion rate equal to about $5 \%$. By consequence, a significant amount of manganese is expected to be in the octahedral cationic sites. The spectrum obtained under a $426 \mathrm{~nm}$ excitation shows a shift of the emission to higher wavelengths. A large band centered at $738 \mathrm{~nm}$ is clearly detected at room temperature. The comparison with our previous study on the non-doped matrix confirms the fact that this red emission is related to the location of manganese in the partially indirect spinel host lattice [3]. For this annealing temperature, the luminescence could be also linked to the occurrence of punctual defects such as the presence of oxygen vacancies in the vicinity of $\mathrm{Zn}_{\mathrm{Al}}$ antisite. But defect emission is not observed anymore under a $426 \mathrm{~nm}$ excitation wavelength. A part of manganese ions could be localized either in distorted five-fold coordinated polyhedra or in regular $\mathrm{AlO}_{6}$ octahedra, substituting for $\mathrm{Al}^{3+}$. One can conclude that the Pechini synthesis has successfully stabilized divalent manganese ions in the $\mathrm{Al}^{3+}$ site with coordination number higher than 4 which makes possible the observation of a red emission for the $\mathrm{Mn}$-doped $\mathrm{ZnAl}_{2} \mathrm{O}_{4}$ spinels. In addition one can say that the large component of the excitation spectrum indicates that the polyhedron of the doping element gets a well-defined and regular geometry.

Due to thermal treatments, divalent cations including the doping element, progressively migrate from the sixfold-coordinated sites to the fourfold-coordinated ones. It could be concluded that increasing the heat treatment temperature, the modification of the emitting properties is clearly visible as the emission switches from the red to the green range.

\subsection{Color switch due to redox phenomenon [5]}

In the $\mathrm{A}_{2} \mathrm{BMX}_{6}$ elpasolite phases, $\mathrm{A}$ and $\mathrm{B}$ belong to the alkali group, $\mathrm{M}$ is a transition metal or a rare earth element, and $\mathrm{X}$ is an halogen [24-26]. Doped with active cation, these materials are studied for various applications as light-emitting 
diodes, laser devices, [27-29] scintillators and detectors, [4,30-31] and for data storage devices. The elpasolite material crystallizes in the cubic system (Fm-3m space group) and can be described as a double perovskite with cationic ordering. The A cation possesses a twelvefold-coordination polyhedron (central cuboctahedral site, 8c Wyckoff position) whereas the $\mathrm{B}$ alkali cation and the $\mathrm{M}$ transition metal/rare earth element regularly alternate along the unit cell axis in a sixfoldcoordinated site (octahedral site).

Concerning the Ce-doped $\mathrm{Rb}_{2} \mathrm{KInF}_{6}$ elpasolite compound, the spectral distributions reflected the substitution of In ${ }^{3+}$ by $\mathrm{Ce}^{3+}$ in the regular octahedra but also the fact that a minor part of $\mathrm{Ce}^{3+}$ ions is located in the cuboctahedron. [5] Under UV irradiation, a redox phenomenon between the Ce/In ions occurs leading to a reversible luminescence switch based on the following equilibrium: $2 \mathrm{Ce}^{3+}+\mathrm{In}^{3+} \rightleftarrows 2 \mathrm{Ce}^{4+}+\mathrm{In}^{+}$. Such a phenomenon is rare and its origin is due to the peculiar crystal structure and composition of the studied material.

The understanding of the luminescent properties requires the doping element cation location. For such a purpose, DFT

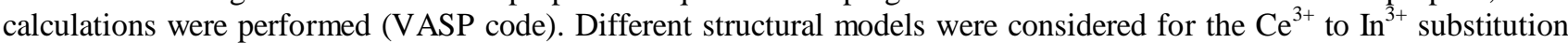
(calculation, within a $2 \mathrm{a} \times 2 \mathrm{~b} \times \mathrm{c} 80$-atoms supercell) in order to evaluate what is the more appropriate substitution site for trivalent cerium. The converged data confirm that cerium cations are preferentially located on the transition metal site (indium site) but this creates an oxidation stress on these latter ions with an equilibrium valence equal to 3.36 . The rubidium site represents a second location of cerium element. The corresponding coordination polyhedron relaxes to form an eightfold-coordinated site but the resulting valence is equal to 2.63 , i.e. in this site, the $\mathrm{Ce}^{3+}$ ions are submitted to reductive stress.

Luminescent spectroscopy was performed on a crushed single crystal grown under controlled atmosphere by the Bridgman-Stockbarger method [5]. As expected the main emission observed under a $315 \mathrm{~nm}$ source is associated with the location of $\mathrm{Ce}^{3+}$ in $\mathrm{In}^{3+}$ octahedral site as illustrated on Figure 3a. The most intense band peaks at $480 \mathrm{~nm}$.

(a)

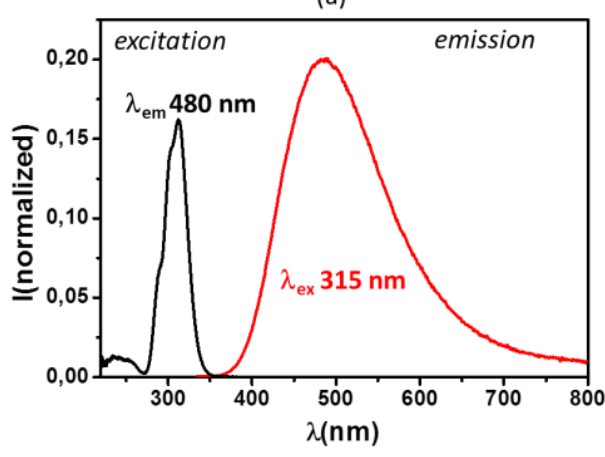

(b)

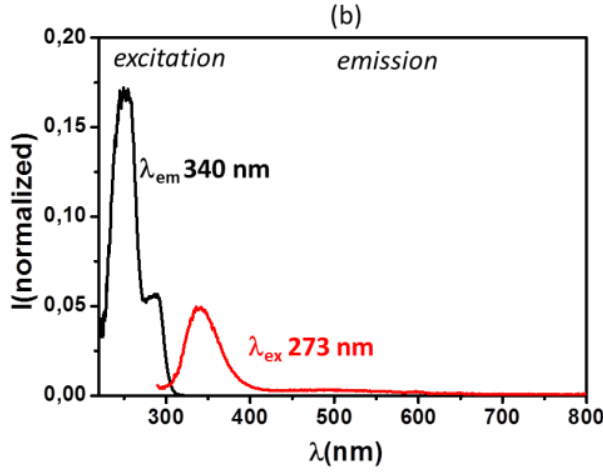

Figure 3. Room temperature excitation and emission spectra of $\mathrm{Ce}^{3+}$ doped $\mathrm{Rb}_{2} \mathrm{KInF}_{6}$ matrix before irradiation, for a) $\mathrm{Ce}^{3+}$ in indium site, and b) $\mathrm{Ce}^{3+}$ in rubidium site.

The complete excitation spectrum is composed of different bands due to the splitting of the $5 \mathrm{~d}$ orbitals under the crystal field effect. The calculated Stokes shift is equal to $10,714 \mathrm{~cm}^{-1}$. In this matrix, the trivalent cerium emission is significantly red-shifted compared with previous literature studies [32,33] and the Stokes shift is more pronounced. A second weaker signal located at $340 \mathrm{~nm}$ is also detected in the Ce-doped $\mathrm{Rb}_{2} \mathrm{KInF}_{6}$ materials (Figure $3 \mathrm{~b}$ ) under a $273 \mathrm{~nm}$ excitation wavelength. The corresponding Stokes shift is equal to $7630 \mathrm{~cm}^{-1}$. We can discard the existence of a secondary phase contribution because of the XRD control performed on a crushed as - grown crystal which showed a pure phase. The final hypothesis is the location of trivalent cerium in a second environment. This effect has already been observed by B. F. Aull et al. in rare earth-doped $\mathrm{Rb}_{2} \mathrm{NaYF}_{6}$ materials; the authors announced a larger site with a higher coordination [32]. We can conclude that this secondary emission corresponds to the contribution of trivalent cerium in the rubidium cuboctahedral site.

Under a $315 \mathrm{~nm}$, the main blue -green emission decreases in favor of a new orange luminescence at $650 \mathrm{~nm}$. This new emission band was attributed by Chaminade et al. and M.A. Buñuel et al. to the $5 \mathrm{~s}^{1} 5 \mathrm{p}^{1} \rightarrow 5 \mathrm{~s}^{2}$ radiative transition of monovalent indium, the UV light making possible the displacement of the following equilibrium: $2 \mathrm{Ce}^{3+}+\mathrm{In}^{3+} \rightleftarrows 2 \mathrm{Ce}^{4+}+\mathrm{In}^{+}$ $[4,34]$. This phenomenon is reversible and an excitation in the monovalent indium absorption band at $255 \mathrm{~nm}$ results in 
an increase of the cerium contribution at $480 \mathrm{~nm}$. Under appropriate UV irradiation, the $4 \mathrm{f}$ cerium electrons are promoted to the $5 \mathrm{~d}$ orbitals. While electrons are in the lowest cerium $5 \mathrm{dT}_{2 \mathrm{~g}}$ orbitals $\left(5 \mathrm{~d}_{\mathrm{xy}}, 5 \mathrm{~d}_{\mathrm{xz}}\right.$ and $\left.5 \mathrm{~d}_{\mathrm{yz}}\right)$, they can be transferred to the neighboring indium orbitals which point in the adequate direction between the fluorine anions. For reminding, the DFT calculations showed that the rare earth ions localized in the indium sites are subject to oxidative stress (valence $>3$ ). The resulting reduction of indium at the monovalent oxidation state gives rise to an $\mathrm{ns}^{2}$ monovalent cation with a highly polarizable electronic doublet. By consequence, a back electron transfer is highly probable.

In this elpasolite matrix which possesses a redox metallic ions pair, luminescence can be monitored under appropriate $\mathrm{UV}$ excitation wavelength because of the succession of $\mathrm{K}-\mathrm{F}-\mathrm{In} / \mathrm{Ce}$ along quasi-collinear axes. A new photochromic inorganic oxide is so obtained.

\subsection{Luminescence and synthetic route [6,9]}

$\mathrm{ZnO}$ is a II-IV wide gap semiconductor material with a large band gap energy of $3.37 \mathrm{eV}$ at room temperature. Typical photoluminescence spectra exhibit two types of emission strongly related to the synthetic route. The UV excitonic recombination is located in the UV part [35-39] whereas the contribution of bulk and surface defects result in large emission band in the visible range [40-43]. The ratio between both contributions depends on the crystallinity rate and the capability to control surface states.

We studied optical properties of $\mathrm{ZnO}$ nanoparticles obtained through organometallic route [8,9] and supercritical fluid route $[6,7]$ as a function of their size and shape. The particle shape control is developed by using different ligands (organometallic route) or precursor concentration and operating parameters as time residence (supercritical fluids route). As an example, SEM pictures of spherical nanoparticles are reported on Figure 4.

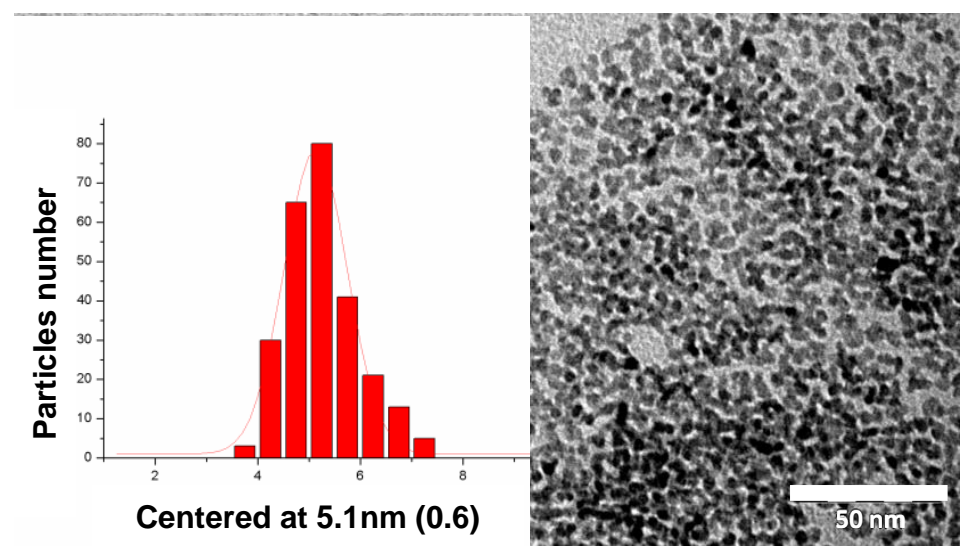

Figure 4. Spherical nanoparticles of $\mathrm{ZnO}$ obtained through organometallic synthetic route

The luminescence properties of these materials were investigated. The corresponding emission graphs are reported on Figure 5. 


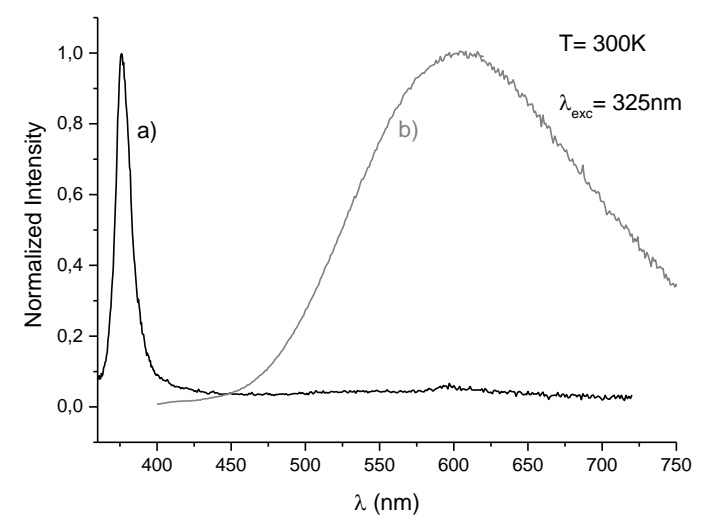

Figure 5. Emission spectra of $\mathrm{ZnO}$ nanoparticles obtained through supercritical fluid route a) and organometallic synthetic route b) under a 325 nm excitation wavelength.

The luminescence of the nanomaterials obtained through organometallic synthesis present a visible emission. The recombination of the photogenerated electron-hole pairs leads to a wide band which is maximum at about $600 \mathrm{~nm}$. The visible luminescence of $\mathrm{ZnO}$ is still subject of controversies. This "yellow orange" emission seems to be linked to the recombination of a shallowly trapped electron with a deeply trapped hole. In this process the photogenerated hole is first trapped by surface defects at the surface of the material. Then it migrates to vacancy levels located in the core of the particle leading to the stabilization of a deep hole trapped level. The emission takes place when the photogenerated hole trapped in the deep defect as an oxygen vacancy recombines with the photogenerated electron trapped in a shallow level located below the conduction band.

The UV excitonic is generally observed for high temperature gas phase routes because these syntheses allow the generation of high crystalline quality $\mathrm{ZnO}$ materials. But the control of the shape and the size of the nanostructures is difficult. The supercritical fluids route makes possible the precipitation of nano-size particles. By controlling the pressure and temperature, it is possible to avoid the stabilization of bulk or surface defects. The lack of trapping levels within the gap makes possible a direct radiative recombination of the photogenerated electron hole pair. By consequence, the resulting emission spectrum is a unique sharp peak peaking in the UV range.

Such optical properties announce significant difference of sensitivity regarding the environment of the nanoparticles and their surface activity.

\section{CONCLUSION}

As demonstrated, photoluminescence can provide a diagnostic on a material. One can play with the temperature to make a doping element migrate within a spinel structure. An evaluation of the thermal history of the compounds can be done. It is also possible to switch the response of a luminescent elpasolite under an appropriate UV excitation beam. Application such as UV detectors or data storages can be proposed by the monitoring of the emission. Finally, once the synthesis route is well-controlled, one can choose to favor UV or visible radiative de-excitation of the well-known ZnO matrix.

\section{ACKNOWLEDGMENTS}

The work was funded by the French National Agency for Research ANR AMOS program (ANR-2010-BLANC-0820), the CNRS, the LaPhIA excellence cluster program (IDEX Université de Bordeaux), the pole de compétitivité Routes de lasers ${ }^{\circledR}$ and the Conseil Régional d'Aquitaine.

\section{REFERENCES}

[1] C. Ronda, Luminescence, from theory to applications, (2008) Wiley VCH, Weinheim

[2] L. Cornu, M. Gaudon, V. Jubera, J. Mater. Chem. C, 1(34), 5419-5428, 2013

[3] L. Cornu, M. Duttine, M. Gaudon, V. Jubera, J. Mater. Chem. C, 2, 9512-9522, 2014 
[4] J. P. Chaminade, A. Garcia, T. Gaewdang, M. Pouchard, J. Grannec, B. Jacquier, Radiat. Eff. Defects Solids, 135, 137-141, 1995

[5] L. Cornu, M. Gaudon, P. Veber, A. Villesuzanne, A. Garcia, V. Jubera, Chem. Eur. J., DOI10.1002/chem.201405784, 21, 2015

[6]Y. Roig, S. Marre, T. Cardinal, C. Aymonier, Angew. Chem. Int. Ed., 123, 12277-12280, 2011

[7] E. Ilin, S. Marre,, V Jubera, C Aymonier, J. Mater. Chem. C, 1(33), 5058-5063, 2013

[8] M.L. Kahn, T. Cardinal, B. Bousquet., M. Monge, V. Jubera, B. Chaudret, ChemPhysChem, 7(11), $2392-2397$ (2006)

[9] A. Glaria, M. L. Kahn, T. Cardinal, F. Senocq, V. Jubera, B. Chaudret, New J. Chem., 32, 662-669, 2008

[10] Z. Lou and J. Hao, Thin Solid Films, 450(2), 334, 2004

[11] K.H. Winbow and J. Cowley, Ceramic Engineering and Science Proceedings, 17(1), 102, 1996

[12] J. Popovic, B. Grzeta, B. Rakvin, E. Tkalcec, M. Vrankic and S. Kurajica, J Alloys Compd, 509(34), 8487, 2011

[13] R.F. Cooley and J.S. Reed, J. Am. Ceram. Soc., 55, 395, 1972

[14] J. Popovic, E. Tkalcec, B. Grzeta, S.. Kurajica and B. Rakvin, Am. Mineral., 94, 771, 2009

[15] J.C. Waerenborgh, M.O. Figueiredo, J.M.P. Cabral and L.C.J. Pereira, J Solid State Chem., 111(2), 300,1994

[16] A. LeNestour. Corrélation structure-propriétés d'absorption UV-Vis-IR associée aux états de valence du cuivre dans des oxydes à base de zinc de type spinelle et würtzite. PhD thesis, Université Bordeaux 1, avril 2006.

[17] H. Matsui, C.-N. Xu, Y. Liu and H. Tateyama. Phys. Rev. B, 69, 235109, 2004

[18] N.J. van der Laag, M.D. Snel, P.C.M.M. Magusin and G. de With, J Eur. Ceram. Soc., 24(8), 2417, 2004

[19] M. Vasile, P. Vlazan, and N.M. Avram, J Alloys Compd, 500(2), 185, 2010

[20] L. Torkian, M.M. Amini and Z. Bahrami, J Inorg. Mater., 26(5), 550, 2011

[21] T. Koskentalo, M. Leskelä and L. Niinistö. Mater. Res. Bull., 20(3), 265, 1985

[22] A. van Die, A.C.H.I. Leenaers, W.F. van der Weg and G. Blasse, Mater. Res. Bull., 22, 781,1987

[23] R. Mlcak and A.H. Kitai, J Lumin., 46(6), 391, 1990

[24] Cross, Ly. J.; Hillebrand, W. J. Z. Kristallogr. Mineral. 12,495, 1887

[25] Meyer, G., Progr. Solid State Chem., 14, 141, 1982

[26] Tanner, P. A., Top. Curr. Chem., 241(Transition Metal and Rare Earth Compounds III), 167-278, 2004

[27] Pedro, S. S.; Sosman, L. P.; Barthem,R. B.; Tedesco, J. C. G.; Bordallo, H. N. J. Lumin., 134, 100, 2013.

[28] Andrews, L. J.; Hitelman, S. M. Ettore Majorana Int. Sci. Ser.: Phys. Sci., 30, 515, 1987

[29] Laroche, M.; Bettinelli, M.; Girard, S.; Moncorgé, R. Chem. Phys. Lett., 311(3-4), 167, 1999

[30] Yang, P.; Zhou, X.; Deng, H.; Rodriguez, M. A.; Feng, P. L.; van Loef, E. V. D.; Shah, K. S.; Doty, F. P. IEEE Trans. Nucl. Sci., 60, 1033, 2013

[31] Glodo, J.; van Loef, E.; Hawrami, R.; Higgins, W. M.; Churilov, A.; Shirwadkar, U.; Shah, K. S. IEEE Trans. Nucl. Sci., 58, 333,2011

[32] Aull, B. F.; Jenssen, Hans P. Phys. Rev. B: Condens. Matter Mater. Phys. 1986, 34, 6647.

[33] Birowosuto, M. D.; Dorenbos, P.; van Eijk, C. W. E.; Kraemer, K. W.; Guedel, H. U.; J. Phys.: Condens. Matter., 18, 6133,2006

[34] Buñuel, M. A.; Moine, B.; Jacquier, B.; Garcia, A.; Chaminade, J. P. J. Appl. Phys., 86, 5045, 1999

[35] A. B. Djurišić et al. Small, 2, 944, 2006

[36] C. F. Klingshirn, ChemPhysChem, 8, 782, 2007

[37] R. Hauschild, H. Priller, M. Decker, J. Brückner, H. Kalt, and C. Klingshirn, Phys. Status Solidi C, 3, 976,2006

[38] C.H. Ahn, S. K. Mohanta, N.E. Lee and H.K. Choa, Appl. Phys. Lett., 94, 261904, 2009

[39] L. Guo, S. Yang, C. Yang, P. Yu, J. Wang, W. Ge, G. K. L. Wong,. Chem. Mater., 12, 2268, 2000

[40] C. X. Xu, X W Sun, X H Zhang, L Ke, S J Chua. Nanotechnology, 15, 856, 2004

[41] D. C. Reynolds, D. C. Look, and B. Jogai, J. Appl. Phys., 89, 6189, 2001

[42] Q. X. Zhao1, P. Klason, M. Willander, H. M. Zhong, W. Lu, J. H. Yang, Appl. Phys. Lett., 87, 211912, 2005

[43] K. Vanheusden, W. L. Warren, C. H. Seager, D. R. Tallant, J. A. Voigt, B. E. Gnade, J. Appl. Phys., 79, 7983, 1996 